\title{
BMJ Open Measuring precarious employment in Sweden: translation, adaptation and psychometric properties of the Employment Precariousness Scale (EPRES)
}

Johanna Jonsson, ${ }^{1}$ Alejandra Vives, ${ }^{2,3}$ Joan Benach, ${ }^{3,4}$ Katarina Kjellberg, ${ }^{1,5}$ Jenny Selander, ${ }^{1}$ Gun Johansson, ${ }^{1,5}$ Theo Bodin ${ }^{1,5}$

To cite: Jonsson J, Vives A, Benach J, et al. Measuring precarious employment in Sweden: translation, adaptation and psychometric properties of the Employment Precariousness Scale (EPRES). BMJ Open 2019;9:e029577. doi:10.1136/ bmjopen-2019-029577

- Prepublication history and additional material for this paper are available online. To view these files, please visit the journal online (http://dx.doi. org/10.1136/bmjopen-2019029577).

Received 31 January 2019 Revised 08 August 2019 Accepted 16 August 2019

Check for updates

(C) Author(s) (or their employer(s)) 2019. Re-use permitted under CC BY-NC. No commercial re-use. See rights and permissions. Published by BMJ.

For numbered affiliations see end of article.

Correspondence to

Johanna Jonsson;

Johanna.Jonsson@ki.se

\section{ABSTRACT}

Objectives Precarious employment (PE) is a determinant of poor health and health inequality. However, the evidence of health consequences and mechanisms underlying the associations, are still limited due to a lack of a comprehensive multidimensional definition and measurement instrument. The Employment Precariousness Scale (EPRES) is a Spanish, multidimensional scale, developed to measure degree of PE. The aim of this study was to translate the EPRES-2010 into Swedish, adapt it to the Swedish context and to assess the psychometric properties of the Swedish EPRES.

Method EPRES was translated, adapted and implemented for data collection within the research project PRecarious EMployment in Stockholm (PREMIS). During 2016-2017, questionnaire data were collected from 483 non-standard employees in Stockholm, Sweden, sampled with webbased respondent-driven sampling. Analyses included item descriptive statistics, scale descriptive statistics and exploratory factor analysis.

Results The final EPRES-Se (Swedish version of the EPRES),consisted of six dimensions and 23 items. There was a high response rate to all items and response options. Global Cronbach's alpha was 0.83 . Subscales 'vulnerability', 'rights' and 'exercise rights' had reliability coefficients between $\alpha=0.78-0.89$ and item-subscale correlations between $r=0.48-0.78$. 'Temporariness' had poor reliability $(\alpha=-0.08)$ and inter-item correlation $(r=-0.04)$, while 'disempowerment' showed acceptable psychometric properties $(\alpha=0.5 ; r=0.34)$. Exploratory factor analysis confirmed the original EPRES factor structure.

Conclusions 'Vulnerability', 'wages', 'rights', 'exercise rights' and 'disempowerment' worked in the Swedish context; however, 'temporariness' would need revising before implementing the EPRES-Se in further research. Continued work and validation of EPRES-Se is encouraged. In order to enable international comparisons and multinational studies, similar studies in other European countries are also called for.

\section{INTRODUCTION}

Precarious employment (PE) is considered a social determinant of poor health and health
Strengths and limitations of this study

- First translation and adaptation of the Employment Precariousness Scale (EPRES)-2010 to Swedish and the Swedish context.

- First assessment of the psychometric properties of the EPRES-Se.

- Relatively small sample restricted to non-standard employees.

- Limited generalisability of results.

inequality. ${ }^{1-3} \mathrm{PE}$ is present in both low-income and middle-income as well as developed countries. ${ }^{45}$ However, evidence of the health consequences of $\mathrm{PE}$, and by which mechanisms PE harm workers' health, is still limited due to the lack of a comprehensive multidimensional definition and measurement instrument. ${ }^{6}$ This lack also brings about challenges in terms of capturing the size of the population in $\mathrm{PE}$, conducting occupational health and safety surveillance, ${ }^{67}$ as well as cross-country comparisons. The Employment Precariousness Scale (EPRES) is a Spanish questionnaire developed to measure six dimensions of PE. EPRES has previously been validated in Spanish and Chilean populations, ${ }^{8-11}$ and also applied to the population of Catalonia, ${ }^{12}$ but as of yet there is no Swedish translation or adaptation.

\section{Precarious employment}

During the past decades, neoliberal economics and policies together with increased globalisation, trade competition, technological innovation and financial crises, has had a considerable impact on the dynamics of the labour market. ${ }^{51314}$ These impacts have had several implications, including an increase in privatisation, downsizing, outsourcing, a 
weakening of union input and collective regulation, and a more competitive and uncertain context for workers with increases in flexible work, unemployment and non-standard employment arrangements. ${ }^{5} 1314$ Furthermore, there has been a decline in attachment to employers, risk shifting from employer to employees, growth in perceived and actual job insecurity and work-based stress, as well as diminished bargaining power and rights. ${ }^{13} 14$

Non-standard arrangements, in comparison with standard employment contracts (ie, open-ended full-time contracts), includes part-time work (underemployment), temporary work, temporary agency work, zero hour contracts, 'gig' work arrangements and self-employment. ${ }^{1471415}$ Non-standard work can also include holding multiple jobs. ${ }^{16}$ A comprehensive term used to describe forms of non-standard employment is ' $\mathrm{PE}$ '. ${ }^{17}$ PE does not, however, solely refer to the type of employment, but also to unfavourable employment conditions, such as vulnerability, low pay, low levels of social security and rights. ${ }^{341417-21}$ As these elements are not exclusively found in non-standard employments per se, employees in a standard employment are also at risk of experiencing precariousness. ${ }^{1422} 23$ Thereby, it is important to move beyond a simplistic categorical grouping of employment, such as temporary versus permanent, and instead work towards a comprehensive multidimensional approach that enables a better understanding of PE. ${ }^{1623}$

Several definitions and attempts to create multidimensional constructs capturing PE already exist. In terms of the previous, Rodgers and Rodgers include employment instability, employment insecurity, lack of protection and economic/social vulnerability as components in their definition of $\mathrm{PE}^{17}$; and the International Labour Organization include low wage, poor protection from termination of employment, lack of access to social protection/benefits (usually associated with full-time standard employment) and lack of/limited access to exercise rights at work. ${ }^{21}$ To our knowledge, two validated questionnaires have been developed for the purpose of measuring PE: The Employment Precarity Index, identifying employment precarity by 10 questions and dividing scores in four groups: secure, stable, vulnerable and precarious ${ }^{23}$; and the EPRES with its six dimensions: 'temporariness', 'wages', 'disempowerment', 'vulnerability', 'rights' and 'exercise rights', where precarity ranges from low to high. ${ }^{10}$ Several studies have also used a combination of indicators as proxy measures in order to identify PE. ${ }^{24-26}$ Despite these efforts, there is of yet no universally accepted definition or operationalisation.

By the means of a cross-national multidimensional definition and measurement instrument of $\mathrm{PE}$, comparative and more precise estimations of health effects would be made possible. Previously, PE has been linked to an array of health issues including mental and physical health ${ }^{27}$ and occupational injuries. ${ }^{28}$ Previous research on related concepts such as job insecurity and temporary employment also show consistent associations with various health outcomes. ${ }^{29-32}$ Mechanisms linking $\mathrm{PE}$ and health are not yet fully understood but pathways that have been suggested include: more harmful working conditions, limited control over one's professional and personal lives, feelings of insecurity and income below the subsistence level, which consequently can affect other social determinants of health such as housing quality, lifestyles and so on. $^{19}$

\section{Employment Precariousness Scale}

EPRES is a Spanish, multidimensional theory-based scale, developed to measure degree of PE among waged and salaried workers. ${ }^{8}$ EPRES is comprised of 22 items and six subscales corresponding to six dimensions: 'temporariness' (contract duration; two items), 'wages' (low or insufficient; possible economic deprivation; three items), 'disempowerment' (level of negotiation of employment conditions; two items), 'vulnerability' (defenselessness to authoritarian treatment; five items), 'rights' (entitlement to workplace rights and social security benefits; four items) and 'exercise rights' (powerlessness, in practice, to exercise workplace rights; six items) ${ }^{89}$ EPRES items are scored on a 5-point or 3-point scale, depending on item, and all items taken together gives a global score ranging between 0 (least precarious) and 4 (most precarious). ${ }^{33}$ EPRES has demonstrated good acceptability, good internal consistency and evidence of construct validity in Spanish and Chilean populations. ${ }^{89}$ The original EPRES scale was revised in 2015 (hereafter known as EPRES-2010), which showed good metric properties and improved sensitivity to worker vulnerability and employment stability. ${ }^{10}$ Further details about EPRES and its development has been described elsewhere. ${ }^{33}$

\section{PE in Sweden}

In Sweden, much of previous research has focused on health outcomes of PE and related exposures. Some studies have focused on exposures such as temporary employment, ${ }^{34}$ peripheral employment ${ }^{35}$ and temporary employment and job insecurity. ${ }^{36}$ Fewer studies have created proxies of multidimensional exposures of PE, for instance by combining previous unemployment, temporary/permanent employment and perceived job insecurity $^{37}$; or by identifying multiple indicators of PE (eg, type of contract, income, working times etc). ${ }^{26}$ It is challenging to put Sweden in a larger comparative context of PE as there is no consensus on its operationalisation. Sweden has, according to some definitions (as defined by a typological approach of 11 indicators), one of the smallest proportions of precarious employees among the Scandinavian countries. ${ }^{19}$ However, in other measures (defined by involuntary part-time work, temporary employment and fear of job-loss) Sweden has the largest proportion of precariously employed individuals ${ }^{24}$ and the largest proportion of fixed-term employment contracts ${ }^{38}$ in the same context. Reports show that the Swedish labour market is growing increasingly more insecure, especially for temporary employees. ${ }^{39} 40$ The proportion of temporary employees has been stable around $15 \%-17 \%$ since 
the late 1990's. ${ }^{40} 41$ There has, however, been reports on a shift within this group where longer-term positions have been replaced by a larger proportion of on-demand employees and day labourers, which are more precarious by nature. ${ }^{39} 4042$ Especially women (19\%, compared with $15 \%$ among men), 16-24 years old (56\%, compared with 21\% among 25-34 years old and 9\% among 35-44 years old) and foreign born (24\%, compared with $15 \%$ among individuals born in Sweden) are likely of holding a temporary employment. ${ }^{40}$ These are groups that reportedly are exposed to high employment precariousness. ${ }^{19}$ Further, around $10 \%$ of employees in Sweden are not covered by collective bargaining agreements and around 9\% have multiple jobs. The latter has seen an increase with 1.5 percentage points since $2005 .{ }^{42}$ According to a definition by the Swedish Labour Policy Council, the group of atypical employees is constituted by those that fulfil one of the following: not being covered by a collective bargaining agreement, have a temporary employment, are employed by a temp agency or are self-employed, have their own company, hold multiple jobs or are working in the informal sector. This group of atypical workers is estimated to be around $35 \%-39 \%$ of the Swedish workforce,$^{42}$ and likely of experiencing precariousness.

Thereby, despite the stabile levels of temporary employment in Sweden, it could be assumed that the level of precariousness has increased on the Swedish labour market. A study from Finland, however, indicate that the precariat (as defined by atypical employment, previous unemployment, fear of job-loss, poor prospects of employment and low earnings) has not seen an increase the past couple of decades. ${ }^{43}$ Without longitudinal studies with precise measures of $\mathrm{PE}$ assessing changes over time, evidence in Sweden remains inconclusive.

To our knowledge, this is the first study in Sweden aiming at translating and adapting a validated multidimensional measurement of PE, EPRES, to Swedish and the Swedish context. It is an important step in the direction to more precisely and fully comprehend the distribution and trends of PE in the Swedish population, as well as it will allow for future studies on health outcomes of PE. Further, such an instrument will also enable well-needed cross-country comparisons.

\section{Aim}

The aim of this study was to translate the EPRES-2010 into Swedish, adapt it to the Swedish context, and to assess the psychometric properties of the Swedish EPRES.

\section{METHOD}

In order to fulfil the study aims, the EPRES-2010 was first translated into Swedish and subsequently adapted to suit the Swedish context (hereafter known as the Swedish version of the Employment Precariousness Scale, EPRES-Se). Thereafter, EPRES-Se was piloted and implemented as a part of the survey used in the research project PRecarious EMployment in Stockholm (PREMIS).

\section{Translation and adaptation of EPRES}

The translation and adaptation process of the EPRES2010 consisted of five steps: (1) translation from Spanish to Swedish; (2) cultural adaptation to fit the Swedish context; (3) back translation to Spanish and adjustments; (4) pilot testing; (5) final adaptations based on user feedback in pilot.

1. The Spanish version of the revised EPRES-2010 scale, which has been published elsewhere, ${ }^{10}$ was translated into Swedish. The translation was done by a bilingual member of the research team (TB) in close discussion with $\mathrm{AV}$, a native Spanish speaker with previous experience of validation studies of EPRES.

2. Several adaptations of the questionnaire were implemented in order to fit Swedish labour market conditions. The questionnaire and its translation was discussed during workshops in the project team, which consisted of Swedish, Spanish and Chilean researchers within public - and occupational health; as well as within the reference group involved in PREMIS, which consisted of labour union members and workers with experience of PE.

3. Several drafts of the Swedish questionnaire were translated back to Spanish during the adaptation process and discussed until the final translation was decided on.

4. A two-stage pilot testing was performed: first face-toface with five volunteers from the reference group, and thereafter online with six volunteers who were currently working but without a permanent full-time employment. The latter were also asked to participate in an evaluation of the survey either via the phone or online.

5. With the input from the pilot, a few minor adaptations were made to the EPRES.

Further, in order to offer non-Swedish speaking participants an opportunity to participate in the PREMIS-study, the PREMIS-survey, including the Swedish version of EPRES, was translated into English by an external, professional, translator. After the translation, minor changes in terms of style and terminology was made by the research group. The English translation of the EPRES-Se was not validated in this study, nor has it been validated in any previous studies.

\section{Implementation of the EPRES-Se}

PREMIS is an ongoing, longitudinal, web-based study conducted in Stockholm county, Sweden. PREMIS aims at methodological development in terms of sampling strategies and assessment of $\mathrm{PE}$, as well as at studying health outcomes of PE. In 2016-2017, 483 non-standard employees were sampled with web-based respondent-driven sampling (webRDS). WebRDS uses peer-to-peer recruitment to build a sample from populations that are hard-to-reach and therefore lacks a sampling frame. ${ }^{44}$ Questionnaire data were collected through an online survey tool specifically developed for respondent-driven sampling (RDS) ${ }^{45}$ The PREMIS-survey 
included all the items of the EPRES-Se, as well as questions on employment type, occupational environment, health outcomes and background. The survey could be completed in Swedish or English.

As one of the aims of PREMIS was to sample precarious employees with webRDS, a process which has been described elsewhere, ${ }^{46}$ participation in the study was restricted to individuals considered particularly vulnerable to PE conditions, such as individuals with temporary employment, on-demand employment, involuntary part-time employment and involuntary self-employment. The inclusion criteria for participants were: living and/ or working in Stockholm County, being aged 18-65 years, having and indicating a Swedish personal identification number, and having a current employment. Exclusion criteria were: having a fixed, full-time, employment, being voluntarily self-employed or being a student. Out of the 483 participants included in the sample, 68 participants were excluded due to not matching criteria of county $(\mathrm{n}=6)$, re-using or giving an incorrect personal number $(n=8$ and $n=17$, respectively), being underage $(n=1)$ or suspected cheating (ie, systematic repeated participation; $\mathrm{n}=36$ ), giving a final sample of 415 participants.

\section{Statistical analysis}

Item descriptive statistics (mean, SD, response frequencies, missing responses and Pearson item-subscale correlations) and scale descriptive statistics (mean, SD, missing items, range, floor and ceiling effects, and reliability (Cronbach's alpha coefficient)) were assessed for the entire sample. Participants answering 'No answer' on the question on income (question three in EPRES-Se) were excluded from the analyses of this question due to the ambiguity of the response alternative. Exploratory factor analysis was conducted in order to determine the underlying factor structure of the data. Principal axis factoring, with varimax rotation, extracting eigenvalues $>1$ was used, which is the method used in previous EPRES-studies. ${ }^{8-10}$ Subanalyses were conducted without informal workers, ie, participants answering 'I have no contract' to the question on contract duration (question one in EPRES-Se). Further, as the sample was recruited with RDS, weighted analyses were conducted in addition to the unweighted analyses. RDSII weights ${ }^{47}$ were calculated in RDS Analyst 0.42 for Windows (Los Angeles, California, USA). In short, weights are based on the self-reported network size in the target population (degree) of the participant and applied in order to account for over-sampling of individuals included in large social networks. Participants with large social networks are given a smaller weight, and vice versa. ${ }^{47}$ The results from the weighted analyses will be shown in full in the online supplementary material. All analyses were performed using SPSS V.23.

\section{Patient and public involvement}

In PREMIS, a reference group consisting of individuals with experience from PE and labour union representatives, was involved in the design of the PREMIS-survey (design of survey and formulation of questions not otherwise standardised) and data collection process (deciding on the appropriate compensation for participation, recruitment of participants and testing the survey software) through active discussions and workshops. Results will be disseminated to study participants through the website of the PREMIS-study.

\section{RESULTS \\ Adaptations of EPRES-Se}

The following adaptations were made to the EPRES-Se in comparison with EPRES-2010.

1. The response alternatives in 'temporariness' were stated as categories, as opposed to free text values of number of days, months or years in EPRES-2010, in order to increase usability in the web-survey context. For the same reason, the question on contract duration which contained three dependent items in EPRES-2010, was collapsed into one question in EPRES-Se. In addition, the response options 'I do not have a contract' was added in order to capture informal work and 'Do not know' was added in order to capture poor contractual relationship.

2. In 'wages', the question on income was presented in local currency (Swedish krona, SEK) and intervals were set to $€ 300$ as the $€ 150-200$ intervals used in the EPRES-2010 version were perceived as too narrow in the Swedish context. In EPRES-2010, intervals were $€ 150-€ 200$ below a monthly income of $€ 1200$, and $€ 300$ above an income of $€ 1201$.

3. In EPRES-2010, the two response alternatives capturing working conditions that were decided unilaterally by the employer, were merged into one response option in the Swedish adaptation in order to enhance usability. Further, as some workers, especially freelancers, are given a fixed budget with no hours specified, the response alternative 'Not applicable. I work project-based' was added for the question on how salary was decided on.

4. One of the items in 'vulnerability', 'afraid to demand better working conditions ...', was taken from the original EPRES $^{8}$ according to the recommendations made by Vives $e t$ al. ${ }^{10}$

5. In 'rights', the question on pension in EPRES-2010, which contained both pension due to old age and disability, was split in two as these are distinct systems unrelated to one another in the Swedish context. Retirement pension (ie, pension due to old age) was kept in EPRES-Se and disability pension was removed. However, a new item assessing the right to sickness benefit was added in the subscale instead, capturing both long term sick leave and shorter spells of sickness absence.

6. In 'exercise of rights' the item on taking a day off for family reasons was clarified by adding "care of a sick child, care of a sick relative and so on' within brackets. 


\section{EPRES-Se}

The final version of EPRES-Se consisted of a total of 23 items and six dimensions: 'temporariness' (two items), 'wages' (three items), 'disempowerment' (two items), 'vulnerability' (five items), 'rights' (five items) and 'exercise rights' (six items). As in the EPRES-2010, the response scales were 5-point ordinal scales for 'temporariness', 5-point ordinal and 5-point frequency scales for 'wages', 5-point frequency scales for 'vulnerability' and 'exercise rights', and 5-point and 3-point categorical scales for 'disempowerment' and 'exercise rights', respectively. See EPRES-Se in online supplementary material A.

\section{Coding of EPRES-Se}

Similarly as EPRES-2010, subscale scores were computed as averages and transformed into a $0-4$ scale. The global EPRES score is the average of the six subscales, ranging from 0 to 4 , where 0 represent the lowest level of precariousness and 4 represent the highest level of precariousness.

For questions in 'temporariness', response options were coded slightly different compared with EPRES2010 in order to accommodate the changes made in the Swedish version. For instance, in the question on duration of contract, response options 'Do not have a contract' and 'Do not know' were coded as 4 (most precarious), in comparison with the Spanish version where a contract length of less than 6 months was coded as 4 . In the question on income, intervals were larger and consistent in size, as compared with the Spanish version. The cut-offs for income were based on the Swedish median net income for 2016, which was just above SEK 18000 for individuals 20-64 years of age. ${ }^{49}$ Merging of items in 'disempowerment' did not affect the coding. The coding of the individual items along with the English translation of EPRES-Se can be found in the online supplementary material B.

\section{Issues leading to recoding of the 'temporariness' dimension}

During the data analysis phase, it was revealed that $79 \%$ $(n=139)$ of the respondents answering 'indefinitely' to the EPRES question on contract length ('How long is your current employment contract valid?') also answered that they were employed on demand/by the hour on a question assessing employment type included in the PREMISsurvey. We suspected that this combination could be a type of 'zero hour' contract, in which the employer is not required to offer the employee any fixed number of hours of work at all per day, week or month. ${ }^{38}$ Thereby, this type of employment situation could be regarded as contingent with a high degree of precariousness. This was confirmed as the group indicating an indefinite contract length and on-demand/by the hour employment, were most similar (in terms of the other EPRES subscales) to employees with a contract lasting $<1$ month and least alike employees with a fixed-term contract $>2$ years. Consequently, we recoded the group with an indefinite contract and on demand/by the hour-employment from
Table 1 Demographic characteristics of the study population (frequencies and percentages), $n=415$

\begin{tabular}{|c|c|c|}
\hline & $\mathbf{N}$ & $\%$ \\
\hline \multicolumn{3}{|l|}{ Age } \\
\hline $18-24$ & 122 & 29 \\
\hline $25-29$ & 185 & 45 \\
\hline $30-64$ & 108 & 26 \\
\hline \multicolumn{3}{|l|}{ Sex } \\
\hline Men & 190 & 46 \\
\hline Women & 225 & 54 \\
\hline \multicolumn{3}{|l|}{ Employment } \\
\hline Temporary employment & 121 & 29 \\
\hline $\begin{array}{l}\text { On demand/by the hour } \\
\text { employment }\end{array}$ & 243 & 59 \\
\hline Self-employment (involuntary) & 13 & 3 \\
\hline Intern & 2 & 1 \\
\hline $\begin{array}{l}\text { Part-time employment } \\
\text { (involuntary) }\end{array}$ & 36 & 9 \\
\hline
\end{tabular}

0 to 3 (ie, the same coding as the response alternative $<1$-month contract). Those with any other employment type and an indefinite contract $(n=36)$ remained coded as 0 . See results of subscale-average comparisons in online supplementary material C.

\section{Psychometric properties of EPRES-Se}

The demographic characteristics of the sample is shown in table 1. The sample consisted of a larger proportion 25-29 years old (45\%) compared with the other age-groups, and a larger proportion women $(54 \%)$ as compared with men. Further, the sample was dominated by workers employed on demand/by the hour (59\%).

Table 2 shows the item-descriptive statistics. There was a small proportion of missing values $(<3 \%)$. Item means were similar within subscales, with the greatest mean difference found within 'wages' (item mean difference=1.6). All response options within the items were used by participants, although to a varying extent. Item-subscale correlations were around $0.6-0.8$ in 'vulnerability' and 'exercise of rights'; and around 0.4-0.6 in 'wages' and 'rights'. There was a weak correlation between item and subscale in 'disempowerment' and no correlation between items in 'temporariness'. With exception of the latter, all items correlated higher with their corresponding subscale compared with other subscales.

Table 3 shows the scale descriptive statistics. The subscale mean scores ranged between 1.4 and 2.3, with a global average of 1.9. The proportion of participants with any missing values in the subscales were around $1 \%$, except in the case of 'wages' where it was 3.1\%. The latter also included participants answering 'No answer' $(\mathrm{n}=9)$. Subscale scores ranged between 0 and 4 , and global scale score ranged between 0.09 and 3.07. Both floor and ceiling effects were generally low $(<5 \%)$, with floor 


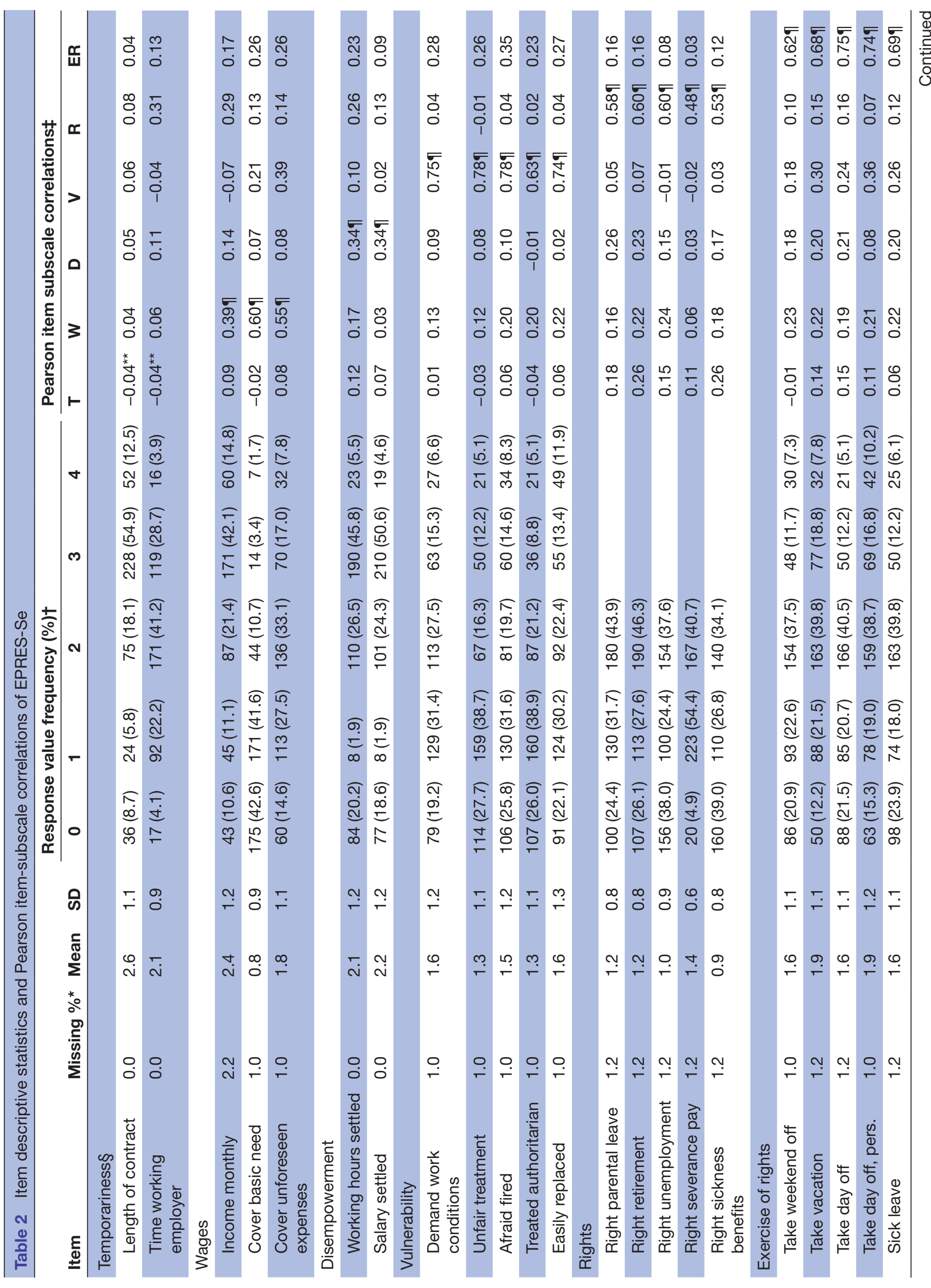


effects being highest for 'disempowerment' (9.2\%) and 'vulnerability' (11.7\%), and ceiling effects being highest for 'rights' $(18.0 \%)$. Cronbach's alpha coefficients were around 0.7 or higher for 'wages', 'vulnerability', 'rights' and 'exercise of rights'. Only 'temporariness' exhibited a Cronbach's alpha coefficient close to 0 . The global alpha coefficient was 0.83 .

The exploratory factor analysis extracted six factors with eigenvalues $>1$ (eigenvalues $=5.3 ; 3.2 ; 2.3 ; 1.6 ; 1.3$; 1.1). The emerging factors were the same as in EPRES2010 , thereby confirming the original factor structure. Together, the six factors explained $64.1 \%$ of the variance. The six factors and their rotated factor loadings are shown in table 4 . All loadings were above 0.35 , except in the case of 'length of contract'.

Subanalyses were conducted in order to investigate the potential effect of including informal workers in the sample $(n=35)$, which had minor influence on the correlation between temporariness-items $(\mathrm{r}=0.002)$ and reliability of the subscale $(-0.003)$. However, in the factor analysis seven factors with eigenvalues $>1$ emerged (5.3; $3.2 ; 2.3 ; 1.6 ; 1.3 ; 1.1 ; 1.0$ ), explaining $68.5 \%$ of the variance. The seventh factor was caused by a split of the temporariness dimension, grouping items on length of contract (duration) and time working for employer (tenure) in separate factors, with factor loadings of 0.33 and 0.42 , respectively.

Analyses for the weighted population sample resulted in virtually the same results in regard to item-subscale correlations, Cronbach's alpha coefficients, floor and ceiling effects, as well as factor loadings from the exploratory factor analysis of EPRES-Se, and did thereby not affect the interpretation of the results. See the weighted results in online supplementary material 1.

\section{DISCUSSION}

\section{Key findings and summary}

EPRES-Se generally performed well, with a small proportion of missing values across all subscales, usage of all response options and good global reliability. The factor structure established in the Spanish EPRES-2010 ${ }^{10}$ was confirmed. The subscales 'vulnerability', 'wages', 'rights' and 'exercise of rights' generally worked well in the Swedish context, with high item-subscale correlations, subscale reliability and factor loadings. However, 'temporariness' did not perform as expected and would need revision. In addition, although 'disempowerment' showed acceptable psychometric properties, the subscale might benefit from additional adaptation.

\section{'Temporariness'}

As opposed to previous studies, ${ }^{8-10}$ temporariness yielded very poor psychometric properties. The items in the subscale did not correlate, there was a negative Cronbach's alpha coefficient and a low factor loading for the item on contract duration. Only minor changes in terms of correlation and Cronbach's alpha was initiated 
Table 3 Scale descriptive statistics: range, mean, SD, floor and ceiling effects and Cronbach's alpha coefficient

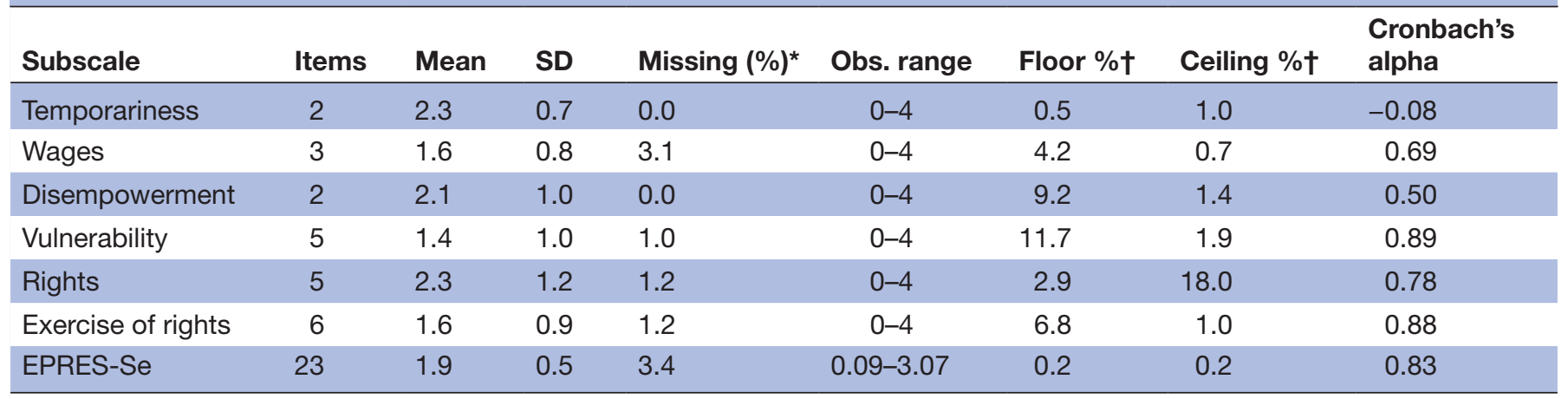

*Proportion of participants with any missing item.

†Proportion of participants with lowest (floor) and highest (ceiling) EPRES-Se scores.

by the removal of informal workers. This subanalysis did, however, split the temporariness dimension in two separate factors, both of which had higher factor loadings. On the basis of these results, we believe that the temporariness dimension needs further development and evaluation in a population of both standard and non-standard employees. Based on the results from the present study, we offer the following thoughts on this matter.

First, it is important to acknowledge the sample selection. As the sample was restricted to non-standard employees (ie, permanent, full-time, employees were excluded), the lower end of the precariousness scale had a smaller proportion than what would be expected if standard employees with longer duration and tenure would have been included in the sample. This limitation is likely to have contributed to the lack of correlation between the items. However, considering that the sample was intentionally recruited in order to capture a population of precariously employed individuals, the poor psychometric properties of temporariness also shows that these items are not necessarily related in a meaningful way when measuring precariousness among non-standard employees.

Second, in the current context, Swedish legislation (the Employment Protection Act SFS 1982:80) prevents an employer to hire an employee for more than 2 years during a 5-year period (consecutive or in shorter repeated contracts) without having to employ (or dismiss) the employee on a permanent contract. ${ }^{50}$ Thereby, an employee with an 18-month tenure might be more precarious than an employee with a 6-month tenure as the latter has longer time left before being forced in or out. Further, approximately $50 \%$ of temporary employees in Sweden has had repeated contracts with the same employer ${ }^{40}$ which is an additional reason that could contribute to the lack of correlation between tenure and duration of contract.

Thirdly, we found that several participants were employed by the hour or on demand while still indicating an indefinite contract length. This highlights the difficulties in assessing temporariness only by contract duration (and tenure). Temporariness is the dimension most likely to be dependent on context. Given the proposed mechanism of temporariness leading to ill-health mediated via feelings of insecurity, temporariness is most relevant in labour markets which do not offer regulatory protection for certain groups of workers, such as permanent employees in most European countries, which does not apply to the same extent in the USA. ${ }^{51}$

However tempting it would be suggest the inclusion of questions regarding 'contract type' in a future development of EPRES, the continuous flexibilisation of the labour market and fast changes in employment practices in combination with contextual differences, makes it increasingly difficult-at least if international comparison using similar scales is sought after.

From a mechanistic standpoint and with an aspiration to develop a scale which could be used in international comparison independent of context, we believe that an item that measures the future employment opportunities with the current employer as objectively as possible should be developed. EPRES-Se and other translations could further be adapted, for example, by combining the contract duration and tenure-items with an item assessing the number of repeated contracts with the same employer or an item assessing how often during a specific time interval the employment contract is up for renewal. Contract duration could also be complemented or replaced by a question more explicitly assessing the remaining duration of the contract at the time of answering the survey.

\section{'Wages'}

The income-item correlated moderately with the other items in the subscale (items assessing how well the income covers basic needs and unforeseen expenses). Previous studies report similar findings for this item. ${ }^{8-10}$ One explanation for these results is the quantitative nature of the income-item compared with the other items. Slightly more than half, $57 \%$, of the participants scored a precariousness level of 3 or 4 on income, which is not surprising as the sample is constituted by young non-standard employees. However, only $5 \%$ and $25 \%$ of the sample scored a precariousness level of 3 or 4 on the other two 
Table 4 Factor loadings from exploratory factor analysis of the EPRES-Se

\begin{tabular}{|c|c|c|c|c|c|c|}
\hline & \multicolumn{6}{|l|}{ Factor } \\
\hline & Exercise rights & Vulnerability & Rights & Wages & Disempowerment & Temporariness \\
\hline \multicolumn{7}{|l|}{ Temporariness } \\
\hline Length of contract & & & & & & 0.12 \\
\hline $\begin{array}{l}\text { Time working } \\
\text { employer }\end{array}$ & 0.12 & & 0.36 & & & -0.36 \\
\hline \multicolumn{7}{|l|}{ Wages } \\
\hline Income monthly & 0.14 & -0.16 & 0.23 & 0.49 & & 0.35 \\
\hline Cover basic need & 0.17 & 0.13 & & 0.71 & & \\
\hline $\begin{array}{l}\text { Cover unforeseen } \\
\text { expenses }\end{array}$ & 0.12 & 0.32 & & 0.79 & & -0.10 \\
\hline \multicolumn{7}{|l|}{ Disempowerment } \\
\hline Working hours settled & 0.17 & & 0.21 & & 0.52 & 0.15 \\
\hline Salary settled & & & & & 0.60 & \\
\hline \multicolumn{7}{|l|}{ Vulnerability } \\
\hline $\begin{array}{l}\text { Demand work } \\
\text { conditions }\end{array}$ & 0.14 & 0.80 & & & & \\
\hline Unfair treatment & 0.11 & 0.84 & & & & \\
\hline Afraid fired & 0.20 & 0.80 & & & & \\
\hline Treated authoritarian & 0.11 & 0.66 & & 0.12 & & 0.13 \\
\hline Easily replaced & 0.12 & 0.77 & & 0.15 & & \\
\hline \multicolumn{7}{|l|}{ Rights } \\
\hline Right parental leave & & & 0.67 & & 0.21 & \\
\hline Right retirement & & & 0.69 & & 0.16 & \\
\hline Right unemployment & & & 0.69 & 0.11 & & 0.29 \\
\hline Right severance pay & & & 0.55 & & -0.10 & \\
\hline $\begin{array}{l}\text { Right sickness } \\
\text { benefits }\end{array}$ & & & 0.60 & & 0.11 & \\
\hline \multicolumn{7}{|l|}{ Exercise rights } \\
\hline Take weekend off & 0.65 & & & 0.10 & & 0.14 \\
\hline Take vacation & 0.70 & 0.18 & & & 0.12 & -0.13 \\
\hline Take day off & 0.80 & 0.10 & 0.10 & & 0.13 & -0.13 \\
\hline Take day off, pers. & 0.78 & 0.24 & & & & -0.10 \\
\hline Sick leave & 0.72 & 0.11 & & & 0.12 & 0.15 \\
\hline Go to doctor & 0.66 & 0.11 & & 0.13 & & \\
\hline
\end{tabular}

Table showing factor loadings $>0.1$.

items, respectively. How well one can cover basic needs and unforeseen expenses could depend on more than income, such as family support. Approximately $24 \%$ of adults aged 20-27 years in Sweden still live at home. In the majority of municipalities in large city regions, this figure is more than $50 \%$. About half of those living at home pay nothing in rent. ${ }^{52}$ As $74 \%$ of the sample is between 18 and 29 years old, it is likely that at least a part of the participants still live at home and receive help from their family. Including standard employees in the sample could potentially have increased the item-subscale correlation as we would expect a larger proportion of participants with a high income.

Aside from the income-item, item-subscale correlations for the remaining two items and subscale reliability were acceptable and only a fraction of the sample did not provide an answer to the item on income $(2.2 \%)$. Therefore, as in the other EPRES scales, we believe the subscale can be used in its current form in future studies.

\section{'Disempowerment'}

The items in 'disempowerment' had acceptable item-subscale correlations and reliability. However, some response 
options ('my working hours/salary was decided within my working team' and 'do not know') were hardly used at all in, indicating that these options might not be appropriate for the current population in the Swedish context. Further, the remaining response options were also inadequate from an adaptational point of view. For example, the working hours/salary being in line with collective bargaining agreements does not imply that the working hours/salary was not set by the employer; these options are not mutually exclusive. In a revised EPRES-Se, the disempowerment-items would benefit from revision and clarification. Combining response options not mutually exclusive could be considered as one way of improving the subscale, such as "my working hours are in accordance with Swedish law and the collective agreement, decided by my employer' and 'my working hours are not in accordance with Swedish law and the collective agreement, decided by my employer'.

\section{'Rights'}

The new item assessing sickness benefit had an acceptable item-subscale correlation and factor loading, similar to the other item-subscale correlations and factor loadings in the subscale, Further, the subscale reliability was good. Taken together, these results point towards that the new item worked well in the subscale.

\section{Strengths and limitations}

This study finds strength in the fact that it is the first study translating and adapting EPRES-2010 to the Swedish context, as well as the first study to assess the psychometric properties of the resulting EPRES-Se. In addition, this work provides context-specific recommendations for future research using EPRES-Se. This study is, however, not without limitations.

The main limitation is the sample. As this study lies within the frame of the PREMIS-project, ${ }^{46}$ the sample was restricted to employees with a non-standard employment. EPRES, however, is developed to measure precariousness independent of the type of employment. ${ }^{8}$ By only assessing the psychometric properties of the scale in a population of non-standard employees, the scale properties cannot be directly compared with similar studies as the heterogeneity of the sample is limited. A sample representative of the entire work force would have provided better insights as to how the scale behaves among Swedish employees. A next step which this study has provided strong grounds for.

Finally, the relatively small sample size could influence the reliability of the results, which should be kept in mind when interpreting and generalising the results. Further, being a convenience sample limits the generalisability of the results. However, as the weighted results confirmed the psychometric properties of the scale, we could expect similar results in a representative sample applying the same sample restrictions.

\section{CONCLUSION}

This study found that EPRES-Se worked well in the current context, with high global reliability, endorsement of all response options (for all items) and few missing values. The psychometric properties for five out of six subscales were satisfactory, considering this being the first translation and adaptation. However, one subscale, 'temporariness', worked poorly and would need revision before implementing the scale in further research. As employment precariousness is an emergent determinant of health it is important that PE can be properly measured. The EPRES-Se is an important step in this direction. We therefore encourage others to continue working with EPRES-Se and to validate it further in populations of both standard and non-standard employees. Our hope is for a revised EPRES-Se with satisfactory psychometric properties to be implemented in research both as an independent tool and within nation-wide surveys. In order to enable international comparisons and multinational studies, similar studies in other European countries are also called for.

\section{Author affiliations}

${ }^{1}$ Institute of Environmental Medicine, Unit of Occupational Medicine, Karolinska Institutet, Stockholm, Sweden

${ }^{2}$ Department of Public Health, Pontificia Universidad Catolica de Chile Escuela de Medicina, Santiago, Chile

${ }^{3}$ Department of Political and Social Sciences, Health Inequalities Research Group, Employment Conditions Knowledge Network (GREDS-EMCONET), Universitat Pompeu Fabra, Barcelona, Spain

${ }^{4}$ Transdisciplinary Research Group on Socioecological Transitions (GinTRANS2), Universidad Autonoma de Madrid, Madrid, Spain

${ }^{5}$ Center for Occupational and Environmental Medicine, Stockholm County Council, Stockholm, Sweden

Acknowledgements The authors are grateful to the PREMIS-project members and reference group members who provided valuable input during the formative work of the study.

Contributors The study was conceived by TB and GJ. All authors, TB, GJ, JJ, AV, $\mathrm{JB}, \mathrm{KK}$ and JS, contributed to the design of the study. TB translated and backtranslated the EPRES, and AV supported the translation process and examined the back translation. JJ collected the data with support from TB and GJ. JJ and TB conducted the analyses. JJ wrote the draft(s) of the manuscript. All authors reviewed the draft(s) and provided feedback on its content. All authors approved the contents of the final manuscript.

Funding This work was supported by grant 2015-00933 from The Swedish Research Council for Health, Working Life and Welfare (FORTE). The funder had no role in study design, data collection and analysis, decision to publish, or preparation of the manuscript.

Competing interests None declared.

Patient consent for publication Informed consent was attained from all participants by the respondent clicking 'Yes' to the question 'I understand the information given above and want to participate'.

Ethics approval Permission from the Regional Ethics Committee of Stockholm was given for the study, with dnr: 2016/1291-31/5.

Provenance and peer review Not commissioned; externally peer reviewed.

Data availability statement Deidentified participant data are from the PREMIS study whose authors may be contacted at johanna.jonsson@ki.se. Data cannot be made publicly available for ethical and legal reasons, but could be made available to researchers who meet the criteria for access to confidential data after approval from the Regional Ethics Committee of Stockholm.

Open access This is an open access article distributed in accordance with the Creative Commons Attribution Non Commercial (CC BY-NC 4.0) license, which permits others to distribute, remix, adapt, build upon this work non-commercially, and license their derivative works on different terms, provided the original work is properly cited, appropriate credit is given, 
any changes made indicated, and the use is non-commercial. See: http:// creativecommons.org/licenses/by-nc/4.0/.

\section{REFERENCES}

1. CSDH. Closing the gap in a generation: health equity through action on the social determinants of health. Final report of the Commission on social determinants of health. Geneva: World Health Organization, 2008.

2. Benach J, Vives A, Amable M, et al. Precarious employment: understanding an emerging social determinant of health. Annu Rev Public Health 2014;35:229-53.

3. Benach J, Muntaner C, Solar O, et al. Employment, work, and health inequalities: a global perspective. Geneva: WHO, 2007.

4. Benach J, Muntaner C. Precarious employment and health: developing a research agenda. J Epidemiol Community Health 2007;61:276-7.

5. Quinlan M, Mayhew C, Bohle P. The global expansion of precarious employment, work disorganization, and consequences for occupational health: placing the debate in a comparative historical context. Int J Health Serv 2001;31:507-36.

6. Benach J, Vives A, Tarafa G, et al. What should we know about precarious employment and health in 2025 ? framing the agenda for the next decade of research. Int J Epidemiol 2016;45:232-8.

7. Howard J. Nonstandard work arrangements and worker health and safety. Am J Ind Med 2017;60:1-10.

8. Vives A, Amable M, Ferrer M, et al. The employment precariousness scale (EPRES): psychometric properties of a new tool for epidemiological studies among waged and salaried workers. Occup Environ Med 2010;67:548-55.

9. Vives-Vergara A, González-López F, Solar O, et al. Precarious employment in Chile: psychometric properties of the Chilean version of employment precariousness scale in private sector workers. Cad Saude Publica 2017;33:e00156215.

10. Vives A, González F, Moncada S, et al. Measuring precarious employment in times of crisis: the revised employment precariousness scale (EPRES) in Spain. Gac Sanit 2015;29:379-82.

11. Vives A, Amable M, Ferrer M, et al. Employment precariousness and poor mental health: evidence from Spain on a new social determinant of health. J Environ Public Health 2013;2013:978656

12. Benach J, Julià M, Tarafa $\mathrm{G}$, et al. La precariedad laboral medida de forma multidimensional: distribución social $Y$ asociación Con La salud en Cataluña. Gac Sanit 2015;29:375-8.

13. Arnold D, Bongiovi JR. Precarious, informalizing, and flexible work: transforming concepts and understandings. Am Behav Sci 2012;57:289-308.

14. Broughton A, Green M, Rickard C, et al. Precarious employment in Europe. Strasbourg: European Parliament, 2016.

15. Muntaner C, Platforms D, Economy G. Digital platforms, Gig economy, precarious employment, and the invisible hand of social class. Int J Health Serv 2018;48:597-600.

16. Vosko LF, Zukewich N, Cranford C. Precarious jobs: a new typology of employment. Perspect labour income 2003;15.

17. Rodgers G, Rodgers J. Precarious jobs in labour market regulation: the growth of atypical employment in Western Europe. International Labour Organisation, 1989.

18. Standing G. Global labour flexibility: seeking distributive justice. London: Macmillan, 1999.

19. Julià M, Vanroelen $\mathrm{C}$, Bosmans $\mathrm{K}$, et al. Precarious employment and quality of employment in relation to health and well-being in Europe. Int J Health Serv 2017;47:389-409.

20. Scott-Marshall H, Tompa E. The health consequences of precarious employment experiences. Work 2011;38:369-82.

21. International Labour Organization. From precarious work to decent work: outcome document to the workers' symposium on policies and regulations to combat precarious employment. Geneva: ILO, 2012.

22. Julià $M$, Vives $A$, Tarafa $G$, et al. Changing the way we understand precarious employment and health: precarisation affects the entire salaried population. Saf Sci 2017;100:66-73.

23. Lewchuk W. Precarious jobs: where are they, and how do they affect well-being? Econ Labour Relat Rev 2017;28:402-19.

24. Kretsos L, Livanos I. The extent and determinants of precarious employment in Europe. Int J Manpow 2016;37:25-43.

25. Van Aerden K, Moors G, Levecque K, et al. Measuring employment arrangements in the European labour force: a typological approach. Soc Indic Res 2014;116:771-91.
26. Oke A, Braithwaite P, Antai D. Sickness absence and precarious employment: a comparative cross-national study of Denmark, Finland, Sweden, and Norway. Int J Occup Environ Med 2016;7:125-47

27. Rönnblad T, Grönholm E, Jonsson J, et al. Precarious employment and mental health: a systematic review and meta-analysis of longitudinal studies. Scand J Work Environ Health 2019.

28. Koranyi I, Jonsson J, Rönnblad T, et al. Precarious employment and occupational accidents and injuries - a systematic review. Scand $J$ Work Environ Health 2018;44:341-50.

29. Kim TJ, von dem Knesebeck O, insecurity Pjob. Perceived job insecurity, unemployment and depressive symptoms: a systematic review and meta-analysis of prospective observational studies. Int Arch Occup Environ Health 2016;89:561-73.

30. Virtanen M, Nyberg ST, Batty GD, et al. Perceived job insecurity as a risk factor for incident coronary heart disease: systematic review and meta-analysis. BMJ 2013;347.

31. Kivimäki Met al. Temporary employment and risk of overall and cause-specific mortality. Am J Epidemiol 2003;158:663-8.

32. De Witte H, Pienaar J, De Cuyper N. Review of 30 years of longitudinal studies on the association between job insecurity and health and well-being: is there causal evidence? Aust Psychol 2016;51:18-31.

33. Vives A. A multidimensional approach to precarious employment: measurement association with poor mental health and prevalence in the Spanish workforce. Universitat Pompeu Fabra, 2010.

34. Waenerlund A-K, Virtanen P, Hammarström A. Is temporary employment related to health status? analysis of the Northern Swedish cohort. Scand J Public Health 2011;39:533-9.

35. Waenerlund A-K, Gustafsson PE, Virtanen P, et al. Is the coreperiphery labour market structure related to perceived health? findings of the Northern Swedish cohort. BMC Public Health 2011;11:956.

36. Virtanen P, Janlert U, Hammarström A. Exposure to temporary employment and job insecurity: a longitudinal study of the health effects. Occup Environ Med 2011;68:570-4.

37. Canivet C, Bodin T, Emmelin M, et al. Precarious employment is a risk factor for poor mental health in young individuals in Sweden: a cohort study with multiple follow-ups. BMC Public Health 2016;16:687.

38. International Labour Organization. Non-Standard employment around the world: understanding challenges, shaping prospects. Geneva, 2016.

39. Alfonsson J. Nomaderna på den svenska arbetsmarknaden. Det otrygga livets framväxt och effekter på klasstrukturen [In Swedish], 2018.

40. Sweden S. Trends for persons in temporary employment [In Swedish], 2015.

41. Eurofund. Non-Standard forms of employment: recent trends and future prospects. International Publications, 2017.

42. The Swedish Labour Policy Council (AER). Olika vägar till jobb [In Swedish] 2018.

43. Pyöriä P, Ojala S. Precarious work and intrinsic job quality: evidence from Finland, 1984-2013. The Economic and Labour Relations Review 2016;27:349-67.

44. Salganik MJ, Heckathorn DD. 5. Sampling and estimation in hidden populations using Respondent-Driven sampling. Sociol Methodol 2004;34:193-240.

45. Bengtsson L, Lu X, Nguyen QC, et al. Implementation of web-based respondent-driven sampling among men who have sex with men in Vietnam. PLoS One 2012;7:e49417.

46. Jonsson J, Stein M, Johansson $G$, et al. A performance assessment of web-based respondent driven sampling among workers with precarious employment in Sweden. PLoS One 2019;14:e0210183.

47. Volz E, Heckathorn DD. Probability based estimation theory for Respondent driven sampling. J Off Stat 2008;24:79-97.

48. Johnston LG, Sabin K. Sampling hard-to-reach populations with Respondent driven sampling. Methodological Innovations Online 2010;5:38.1-48.

49. Statistics Sweden. Inkomstrapport 2016 Hushåll och Individer [In Swedish], 2016.

50. Svensk författningssamling. Lagen(1982:80) om anställningsskydd (SFS 2017:363), 2017.

51. OECD. Detailed description of employment protection legislation, 2012-2013. OECD countries, 2013.

52. Hyresgästföreningen. Unga vuxnas boende [In Swedish], 2018. 